\title{
Experimental and Computational Investigations of Baffle Location Effect on the Performance of Oil and Water Separator Tanks
}

\author{
Rozi Abdullah ${ }^{1, a}$, Haitham A. Hussein ${ }^{1,2}$ and Md Azlin Md Said ${ }^{1}$ \\ ${ }^{1}$ School of civil engineering, Universiti Sains Malaysia, 14300 Nibong Tebal, P. Penang, Malaysia \\ ${ }^{2}$ Civil Engineering Department, Al-Nahrain University, Baghdad, Iraq
}

\begin{abstract}
Gravity separator tanks are used to separate oil from water in treatment units. Achieving the best flow uniformity in a separator tank will improve the maximum removal efficiency of oil globules from water. In this study, the effect on hydraulic performance of different baffle structure positions inside a tank was investigated. Experimental data and 2D computation fluid dynamics were used for analysis. In the numerical model, two-phase flow (drift flux model) was used to validate one-phase flow. For laboratory measurements, the velocity fields were measured using an acoustic Doppler velocimeter. The measurements were compared with the result of the computational model. The results of the experimental and computational simulations indicate that the best location of a baffle structure is achieved when the standard deviation of the velocity profile and the volume of the circulation zone inside the tank are minimized.
\end{abstract}

\section{Introduction}

The water pollution control ordinance imposes an absolute prohibition on the discharge of oil or oily mixtures to public foul sewers. Fat, oil, and grease (FOG) blockages are the primary cause of $40 \%$ to $50 \%$ of all sanitary system overflows [1]. FOG may accumulate inside sanitary systems and eventually reduce the effective size of such systems [2]. These waste materials include source waste from petroleum and petrochemical refining and processing; tramp oil from mechanical repair stores, utility operations, restaurants, sanitary sewage, and bilge and ballast water; and contaminated surface runoff [3].

A gravity separation tank operates based on the specific gravity difference between water and immiscible oil globules. The effectiveness of a gravity separator depends on appropriate hydraulic design and period of wastewater detention for a given rise velocity. Construction baffle structure is one of the most effective ways to improve the separation of oil and water by enhancing the flow pattern and increasing the hydraulic retention time inside separator tanks.

Scientific studies conducted to establish design guidelines for oil and water separator tanks are limited. Septic tanks that provide at least $10 \mathrm{~min}$ to $30 \mathrm{~min}$ hydraulic retention time are suggested for adequate oil and grease removal [4]. Chu and $\mathrm{Ng}$ [2] investigated whether installing tube settlers in a grease intercepter design can improve performance. They used peanut oil with water and measured the

\footnotetext{
a Corresponding author : cerozi@usm.my
} 
effluent oil and grease as well as the chemical oxygen demand. Their research showed that an $8 \%$ to $10 \%$ improvement in removal efficiency can be achieved for oil and grease by adding tube settlers.

The present research mainly aims to determine the best location of a single baffle inside rectangular gravity separation tanks. Such location must correspond to the optimum flotation of oil droplet performance in a tank. In this study, the effect of baffle position on separation efficiency is investigated through experimental and numerical simulations using two-phase flows, oil, and water. The appropriate location of the baffle in a separator tank is determined using computational fluid dynamics CFD. The volume of fluid (VOF) method is used for numerical method. In the laboratory, the velocity fields in the flume tank are measured by using an Acoustic Doppler Velocimeter (ADV), and the measurements are used to validate the numerical models. The ADV uses a technique known as pulse to pulse coherent Doppler sonar to measure the velocity vectors in 3D.

\section{Laboratory Model}

\subsection{Laboratory setup details}

A set of laboratory measurements is conducted for four baffle distances from the tank inlet over the length of basin ratios of a thin baffle in a rectangular oil and water separator tank (with water depthto-tank length ratio of 0.31 ) to validate the performance of oil and water separator tanks via computation simulation [5, 6]. Figure1 illustrates the experimental setup and measurement system. This figure shows a rectangular oil and water separator tank with length $L=130 \mathrm{~cm}$, width $W=50 \mathrm{~cm}$, height $H=42 \mathrm{~cm}$, height of inlet opening $H_{\text {in }}=10 \mathrm{~cm}$, height of weir $H_{\mathrm{w}}=40 \mathrm{~cm}$, and height of baffle $H_{\mathrm{b}}=31.8 \mathrm{~cm}$. The distance from the tank bottom to the inlet opening $H_{1}=15 \mathrm{~cm}$. The laboratory experiments are conducted for four baffle positions at a flow rate equal to $Q=2 \mathrm{~L} / \mathrm{s}$. In cases 1 to 4 , a baffle is located at various baffle distances from the inlet-to-tank length ratios, that is, $d / L=0.46,0.61$, 0.77 , and 0.93. Experimental measurements of the cases are conducted, and the measured values of dimensionless $x$ - and $z$-velocity profiles are recorded. The three velocity components are measured using an ADV. The ADV is relatively rugged, easy to operate, and can be readily mounted and maneuvered with the flow field. A $10 \mathrm{MHz}$ Nortek acoustic Doppler velocity meter (Nortek AS, Norway) is used to measure the instantaneous velocities of liquid flow at different points in the oil and water separator tank. In this study, seven profiles are used to measure the velocity in the separator tanks for each case of baffle location. The velocity of each profile is then measured at eight points along the vertical line.

\subsection{CFD model}

\subsubsection{Time-averaged flow equations}

In hydraulic numerical modeling, the incompressible steady state flow with viscous effect is often considered to determine flow conditions. The mass continuity and momentum equations are generally used as governing equations, and the turbulence flow model is used with these equations to calculate the Reynolds stresses. The general mass continuity equation is $[7,8]$ :

$$
V_{f} \frac{\partial \rho}{\partial t}+\frac{\partial}{\partial x}\left(\rho u A_{x}\right)+\frac{\partial}{\partial z}\left(\rho w A_{z}\right)=0
$$

where $V_{f}$ is the fractional volume open to flow in the calculation cell; $\rho$ is the fluid density; and $u$ and $w$ are the velocity components in the length and height $(x, z)$ directions, respectively. The momentum equation for the fluid velocity components in the two directions are the Navier-Stokes equations expressed as: 


$$
\begin{aligned}
& \frac{\partial u}{\partial t}+\frac{1}{V_{f}}\left\{u A_{x} \frac{\partial u}{\partial x}+w A_{z} \frac{\partial u}{\partial z}\right\}=-\frac{1}{\rho} \frac{\partial P}{\partial x}+G_{x}+f_{x} \\
& \frac{\partial w}{\partial t}+\frac{1}{V_{f}}\left\{u A_{x} \frac{\partial w}{\partial x}+w A_{z} \frac{\partial w}{\partial z}\right\}=-\frac{1}{\rho} \frac{\partial P}{\partial z}+G_{z}+f_{z}
\end{aligned}
$$

where $G_{x}, G_{z}$ are the body accelerations, and $f_{x}, f_{z}$ are the viscous accelerations that form a variable dynamic viscosity.

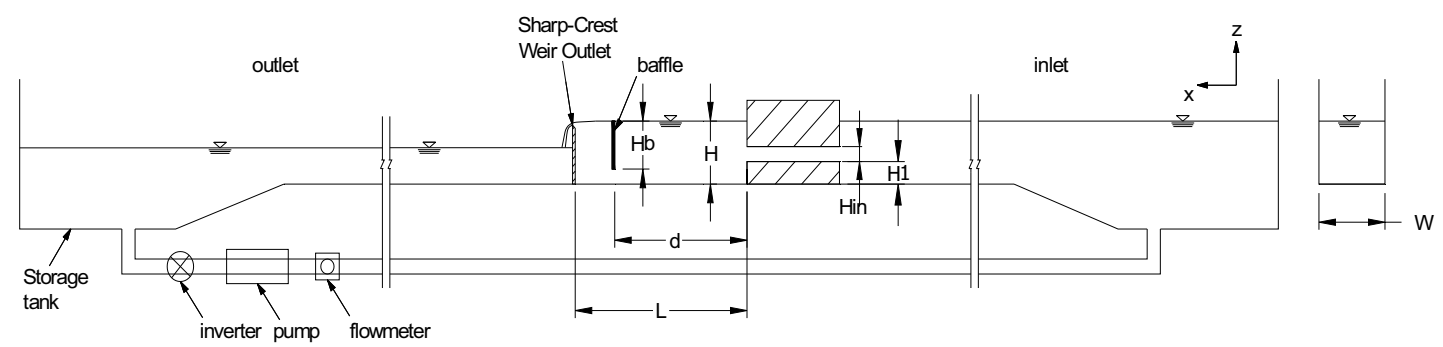

(a)

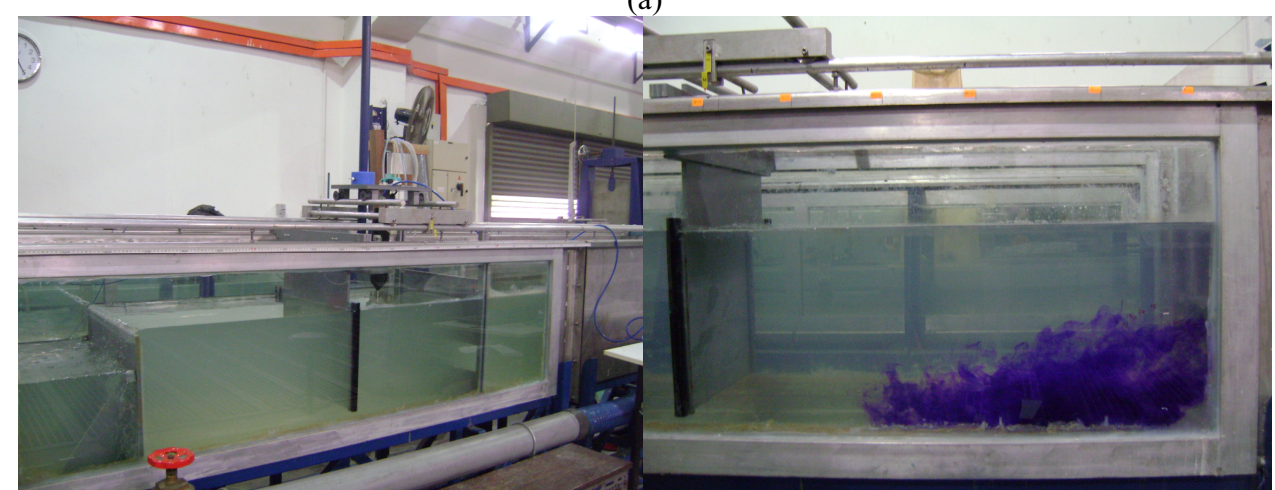

(b)

Figure 1. (a) Schematic diagram of the tank; (b) Photos of laboratory setup.

\subsection{Drift flux model}

In a fluid consisting of multiphase components, such as oil and water, wherein the components have different densities, the components also have different flow velocities. The two-phase (oil and water) numerical simulation is based on the drift flux model. The drift flux formulation of relative velocity assumes that flow is composed of two discrete phases: the continuous phase (water) and the dispersed phase (oil). The volume fractions of the two components that make up the mixture are denoted by $f_{1}$ and $f_{2}$, respectively, where :

$$
f_{1}+f_{2}=1
$$

The momentum balance for the water phase is

$$
\frac{\partial u_{1}}{\partial t}+u_{1} \cdot \nabla u_{1}=-\frac{1}{\rho_{1}} \nabla P+F+\frac{K}{f \rho_{1}} u_{r}
$$


The momentum balance for the oil phase is

$$
\frac{\partial u_{2}}{\partial t}+u_{2} \cdot \nabla u_{2}=-\frac{1}{\rho_{2}} \nabla P+F-\frac{K}{(1-f) \rho_{2}} u_{r}
$$

where $u_{1}$ and $u_{2}$ are the microscope velocities of the water (continuous) and oil (dispersed) phases, respectively; and $f$ is the volume fraction of the continuous phase. The microscopic velocity refers to the velocity of each phase with a small but finite volume of fluid. $K$ is a drag coefficient that relates to the interaction of the two phases, $F$ is the bodily force, and $u_{r}$ is the relative velocity difference between the dispersed and continuous phases.

$$
u_{r}=u_{2}-u_{1}
$$

The aim of the drift flux model is to compute for the motion of the two phases relative to the volume average velocity $\bar{u}$. The volume weighted average velocity is

$$
\overline{\mathrm{u}}=f \mathrm{u}_{1}+(1-f) \mathrm{u}_{2}
$$

\subsection{Verification test}

The flow in an oil and water separator tank has two phases. In this study, one and two phase numerical models in the computation simulation of separation tanks are used. The oil phase is in the form of drops with an average diameter of $150 \mu \mathrm{m}$ and a density of $910 \mathrm{~kg} / \mathrm{m}^{3}$. Water is discharged through the inlet slot at a flow rate of $2 \mathrm{~L} / \mathrm{s}$, whereas the inlet slot of $5 \%$ by volume oil [9] in water mixture has a constant discharge rate equal to $30 \mathrm{mg} / \mathrm{L}$. $300 \times 122$ grids were chosen for the computation. Figure 2 shows a comparison of the velocity profile of the numerical model using the FLOW-3D program between the one-phase and two-phase flow models (drift flux model).

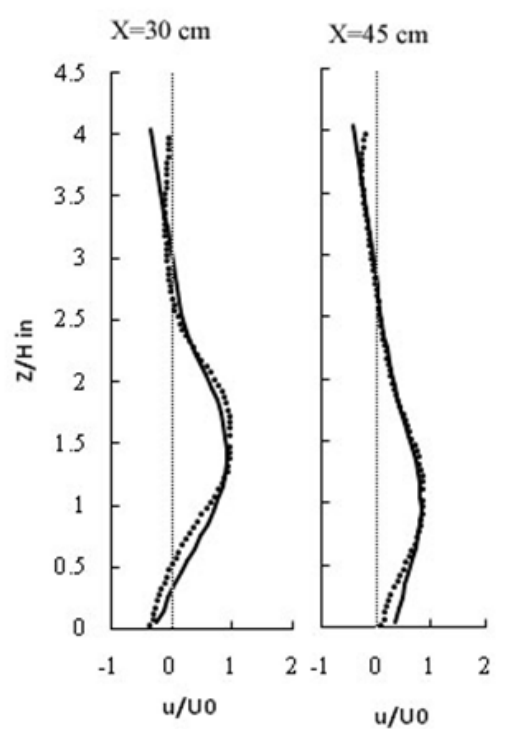

(a)

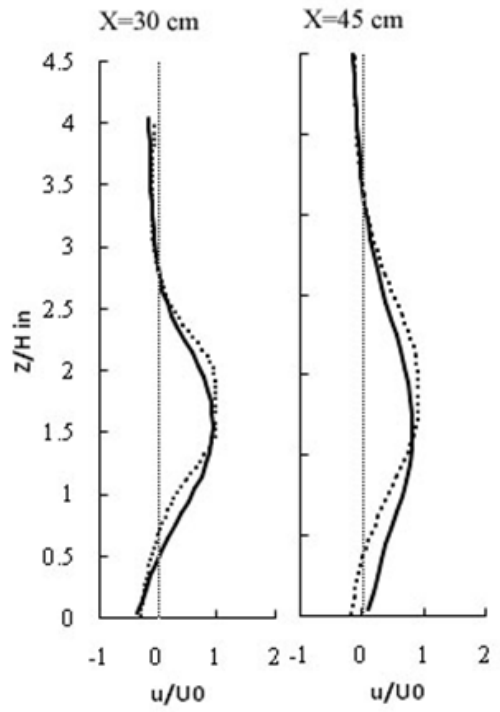

(b)

One Phase Flow Model

Drift Flux Model

Figure 2. $x$-Velocity profile for one and two phase flow model for baffle height $(\mathrm{Hb} / \mathrm{H}=0.76)$ at $\mathrm{d} / \mathrm{L}=0.77$. 
The velocity profiles of the two models are computed at $30 \mathrm{~cm}$ and $45 \mathrm{~cm}$ from the inlet for cases of baffle location at $d / L=0.46$ and 0.77 . The velocity is computed in the $x$ and $z$ direction. The aforementioned profiles show that the velocities in the numerical simulation are in good agreement between one-phase flow (water) and two-phase flow (oil and water). Consequently, for these velocity profiles, the flow in the experimental model used pure water without oil droplet. Figure 3 shows the $x$ computed velocity profiles compared with the experimental measurements for cases of baffle location $d / L=0.77$ inside the oil and water separator tanks. The 2D CFD model is a good descriptor of the experimental measurements.
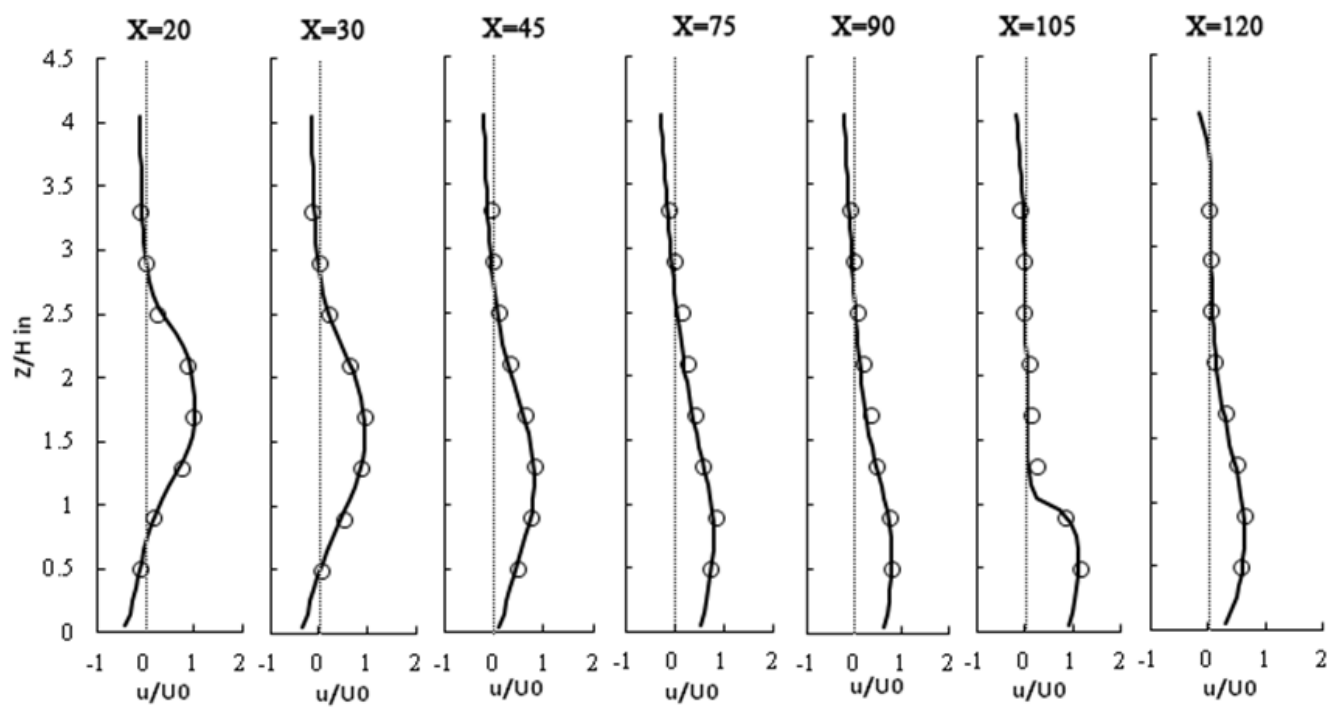

(b)

\section{Experimental Data}

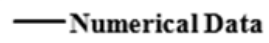

Figure 3. $x$-Velocity profile for for baffle height $(\mathrm{Hb} / \mathrm{H}=0.76)$ at $\mathrm{d} / \mathrm{L}=0.77$.

\section{Results and Discussions}

\subsection{Velocity profile}

In two phase flow (oil and water) the rise of oil droplets (vertical velocity) in water generally depends on the density and viscosity of water. Moreover, the vertical velocity of oil droplets is highly dependent on droplet diameter, with small droplets rising significantly more slowly than large droplets. Consequently, the separator tank must be designed to reduce the inlet horizontal velocity as much as possible and to achieve more uniformity. This situation allows oil droplets to coalesce with other droplets and to rise rapidly toward the separator surface. The effectiveness of baffle location in improving the uniformity of the flow pattern has been assessed by comparing the standard deviation (SD) of $x$-velocity across the cross section [10]. For each baffle location case, the axial velocity is retrieved at 82 equally spaced points along five vertical positions in the separator tank, and then, the $\mathrm{SD}$ is calculated. Figure 4 shows the SD of $\mathrm{x}$-velocity across the separator tank with four end baffle position $(d / L)$. It can be seen that the baffle location at $d / L=0.77$ has the minimum magnitude (SD) along the separator tank from 0.1 to $0.5 \mathrm{~m}$, and thus, it exhibits the best performance (a better separator). 


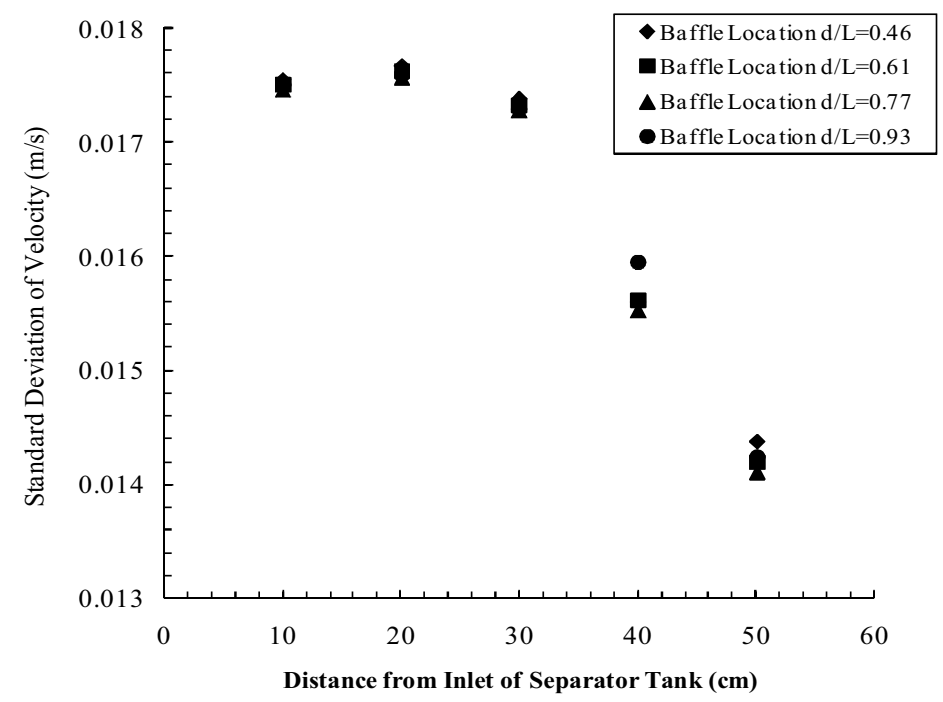

Figure 4. Standard deviation of velocity across the Separator tanks with different baffle locations d/L two phase flow.

\subsection{Flow field}

The high performance of separator tanks depend on the flow pattern. Therefore the baffle structure in the separator tanks is used as to reduce the energy dissipaters, circulation zone volume inside the tank, and in additional to collect the oil droplet from the water surface level. The best position of the baffle is acquired when the volume of circulation zone is minimized. Thus, the proper position for the baffle may achieve to obtain more uniform distribution of velocity in the separator tanks and minimize dead zone. Four different cases of baffle positions were modeled in this study. Figure 5 illustrate shows the baffles locations with the volume of vortices or circulation zone, which is intended by the total water volume in separator tanks and calculated by the numerical method. This figure illustrate The baffle position at $d / L=0.46,0.61$ and 0.93 has $66 \%, 65 \%$ and $60 \%$ circulation volume rate respectively, while the minimum circulation volume rate magnitude in case of $d / L=0.77$ is $59 \%$ from total tank volume.

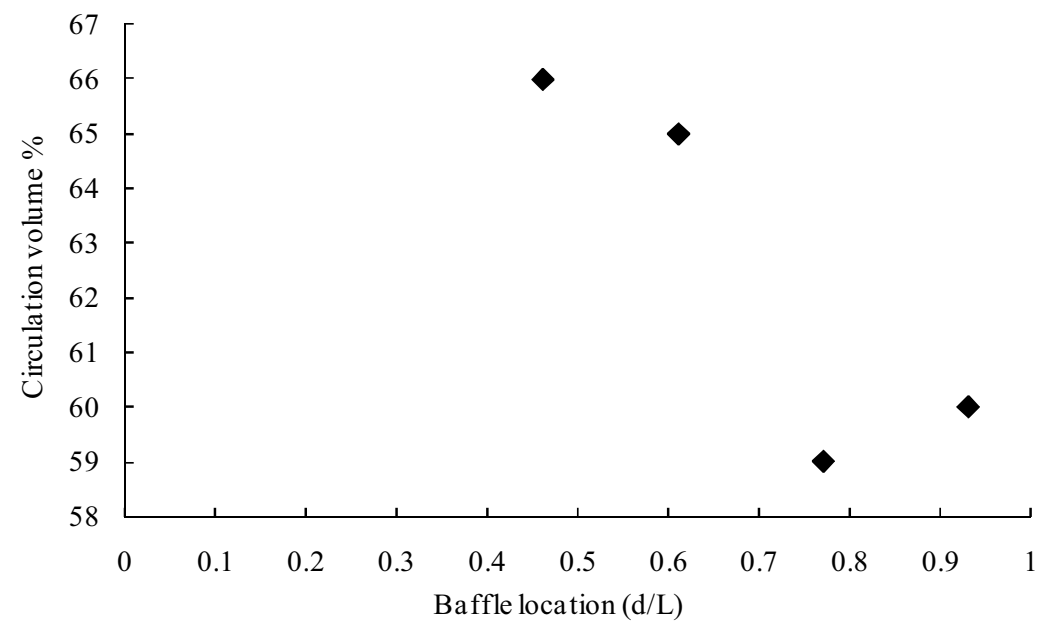

Figure 5. Circulation volume percentages in different baffle location $(d / L)$. 


\section{Conclusion}

This study was performed to evaluate the performance of oil and water gravity separator tanks. Laboratory experiments and CFD analysis were performed to assess the effect of baffle positions $d / L=0.46,0.61,0.77$, and 0.93 on the removal efficiency of oil and water separator tanks. A numerical model was applied to determine the effect of baffle position on velocity profile. Standard deviation served as an indicator of flow uniformity along separator tank sections. The minimum SD resulted in the best uniformity (a better separator). Moreover, the volume of vortices or the circulation zone was normalized to determine the smallest circulation zone in each baffle position case in the separator tank. The results showed that the baffle constructed on $d / L=0.77$ achieves the minimum SD and volume of circulation zone percentage.

\section{References}

The authors would like to acknowledge Universiti Sains Malaysia for funding this research through RUI grant (1001/PAWAM/814194).

\section{References}

[1] R. Southerland, Sewer fitness: Cutting the fat, American City and Country, 117, 27-31, (2002).

[2] W. Chu and F.L. Ng, Upgrading the conventional grease trap using a tube settler, Environment International, 26, 17-22, (2000).

[3] A.O. Abass, A.T. Jameel, S.A. Muyubi and M.I. Abdul Karim, Removal of oil and grease as emerging pollutants of concern (EPC) in wastewater stream, IIUM Engineering J., 12(4), 161$169,(2011)$

[4] I. Metcalf, Wastewater Engineerin: Treatment and Reuse: McGraw-Hill, (2003)

[5] API, Design and operation of oil-water separators, American Petroleum Institute, Washington, (1990).

[6] T. Morrow and F. Dodget, Fluid flow modelling of gravity separators, Multi-Phase Production, 364-380, (1991).

[7] C. Hirt and J. Sicilian, A porosity technique for the definition of obstacles in rectangular cell meshes, Proc. of 4th Int. Conf. on Numerical Ship Hydrodynamics, Washington, (1985).

[8] C.W. Hirt and B.D. Nichols, Volume of fluid (VOF) method for the dynamics of free boundaries, J. of Computational Physics, 39, 201-225, (1981).

[9] T.N. Aziz, L.M. Holt, K.M. Keener, J.W. Groninger and J.J. Ducoste, Performance of grease abatement devices for removal of fat, oil, and grease, J. of Environmental Engineering, 137, 8492, (2011).

[10]D. Wilkinson, B. Waldie, M.I. Mohamad Nor and H.Y. Lee, Baffle plate configurations to enhance separation in horizontal primary separators, Chemical Engineering J., 77, 221-226, (2000). 